\title{
Avaliação de microorganismos presentes em aparelhos celulares utilizados por profissionais de saúde: um estudo realizado em um hospital da Baixada Fluminense (RJ)
}

\author{
Evaluation of microorganisms in cellular appliances used by healthcare professionals: a \\ study carried out in a hospital of Baixada Fluminense (RJ)
}

Evaluación de microorganismos en aparatos celulares utilizados por profesionales sanitários: estudio realizado en un hospital de Baixada Fluminense (RJ)

Haluysio Silva Netto ${ }^{1}$, Anderson da Silva Santos ${ }^{1}$, Letícia Moreira de Souza ${ }^{1 *}$.

\begin{abstract}
RESUMO
Objetivo: Investigar as bactérias presentes nos aparelhos dos profissionais de saúde que atuam em quatro áreas distintas do hospital: Unidade de Terapia Intensiva (UTI), Centro Cirúrgico, Emergência e recintos estritamente administrativos, este último constitui o grupo de controle. Métodos: Foi realizado um estudo transversal aplicado em um hospital a partir de 120 amostras coletadas dos telefones celulares de profissionais que atuam em setores de especialidades distintas. Para isso, seus swabs foram cultivados em meio Ágar em placas de cultura e suas leituras realizadas em 24 e 48h, os resultados então foram diferenciados em conformidade com as especialidades. Resultados: Do total de aparelhos (120) avaliados, 92,5\% (111) estavam colonizados por um ou mais tipos de bactérias. O tipo de bactéria mais frequente foi o Staphylococcus coagulase-negativa (51\%), seguido do Staphylococcus aureus MRSA (6\%), Acinetobacter baumannii (3,3\%) e Klebsiella pneumoniae $(1,6 \%)$. Conclusão: Como identificado em outros estudos que confirmaram a contaminação de aparelhos celulares de profissionais no ambiente hospitalar, estes dispositivos podem servir como agentes carreadores de bactérias potencialmente patogênicas. Isto posto, medidas para regulamentar seu uso e a necessidade de revisão dos protocolos de higiene fazem-se indispensáveis.
\end{abstract}

Palavras-chave: Infecção, Infecção hospitalar, Telefone celular.

\section{ABSTRACT}

Objective: To investigate the bacteria present in the equipment of health professionals who work in four different areas of the hospital: Intensive Care Unit (ICU), Surgical Center, Emergency and strictly administrative premises, the latter constituting the control group. Methods: A cross-sectional study was carried out in a hospital based on 120 samples collected from cell phones of professionals working in sectors with different specialties. For this, their swabs were grown on Agar medium in culture plates and their readings were performed in 24 and 48 hours, the results were then differentiated according to the specialties. Results: Of the total of devices (120) evaluated, $92.5 \%$ (111) were colonized by one or more types of bacteria. The most frequent type of bacteria was coagulase-negative Staphylococcus (51\%), followed by Staphylococcus aureus MRSA (6\%), Acinetobacter baumannii (3.3\%) and Klebsiella pneumoniae (1.6\%). Conclusion: As identified in other studies that confirmed the contamination of cell phones of professionals in the hospital environment, these devices can serve as carriers of potentially pathogenic bacteria. That said, measures to regulate its use and the need to review hygiene protocols are indispensable.

Key words: Infection, Cross infection, Cell phones.

1 Universidade Iguaçu (UNIG), Nova Iguaçu - RJ. *E-mail: letmoreira72@gmail.com 


\section{RESUMEN}

Objetivo: Investigar las bacterias presentes en los equipos de los profesionales de la salud que laboran en cuatro áreas diferenciadas del hospital: Unidad de Cuidados Intensivos (UCl), Centro Quirúrgico, Urgencias y local estrictamente administrativo, constituyendo este último el grupo de control. Métodos: se realizó un estudio transversal en un hospital a partir de 120 muestras recogidas de teléfonos móviles de profesionales que laboran en sectores de diferentes especialidades. Para ello, sus hisopos se cultivaron en medio Agar en placas de cultivo y sus lecturas se realizaron en 24 y 48 horas, luego se diferenciaron los resultados según las especialidades. Resultados: Del total de dispositivos (120) evaluados, el 92,5\% (111) fueron colonizados por uno o más tipos de bacterias. El tipo de bacteria más frecuente fue Staphylococcus coagulasa negativo (51\%), seguido de Staphylococcus aureus MRSA (6\%), Acinetobacter baumannii (3,3\%) y Klebsiella pneumoniae $(1,6 \%)$. Conclusión: Como se identificó en otros estudios que confirmaron la contaminación de teléfonos celulares de profesionales en el ambiente hospitalario, estos dispositivos pueden servir como portadores de bacterias potencialmente patógenas. Dicho esto, las medidas para regular su uso y la necesidad de revisar los protocolos de higiene son indispensables.

Palabras clave: Infección, Infección hospitalaria, Teléfono celular.

\section{INTRODUÇÃO}

O ambiente hospitalar é um local favorável à propagação de micro-organismos patogênicos por estar ocupado por pacientes colonizados e/ou infectados por tais patógenos, bem como a presença de bactérias em aparelhos e superfícies inanimadas é muito comum (OLIVEIRA AC e DAMASCENO QS, 2010). Na Portaria no 2.616 de 12 de maio de 1998 do Ministério da Saúde (MS), define como Infecção hospitalar aquela "adquirida após a admissão do paciente e que se manifeste durante a internação ou após a alta, quando puder ser relacionada com a internação ou procedimentos hospitalares" (BRASIL, 1998). As Infecções Relacionadas à Assistência à Saúde (IRAS) apresentam impacto sobre letalidade hospitalar, tempo de internação e sobre os custos.

Neste cenário deve-se considerar também o aumento da resistência bacteriana, o que tem colocado as IRAS entre os principais problemas enfrentados pela saúde pública no Brasil (OLIVEIRA AC, et al., 2009). Com dados que apontam para o aumento do número de infecções hospitalares no Brasil, é preciso levar em consideração os impactos causados no sistema público de saúde, já que tratar pacientes acometidos por essas infecções custa três vezes mais do que pacientes sem infecção (PRADES SS, et al., 1995). O efeito dessas complicações infecciosas para o paciente resulta em aumento do tempo de internação ou reincidências, sequelas, incapacidade para o trabalho, gasto com medicação e óbito.

Apesar da legislação em vigor, estima-se que as taxas de IRAS no Brasil ainda são altas e constituem 14\% das internações (BRASIL, 2019). A ocorrência das IRAS tem um maior impacto no Sistema Único de Saúde (SUS), entre os hospitais que notificaram IRAS no ano de $2016,71,3 \%$ possuem vínculos com o SUS (ANVISA, 2016). De acordo com dados oficiais, no Brasil, os sítios de infecção hospitalar mais frequentemente atingidos são o trato urinário, feridas cirúrgicas, trato respiratório e sangue. Entre os agentes mais comuns relacionados com esse cenário de infecções, destacam-se o Staphylococcus epidermidis, Staphylococcus aureus e Klebsiella sp (ANVISA, 2004).

Outro gênero de bactéria de grande relevância clínica tanto pela sua incidência, quanto pela sua resistência aos antibióticos, é o Acinetobacter baumannii, estima-se que a mortalidade bruta geral por infecção da corrente sanguínea por Acinetobacter baumannii seja de 34,0\% a 43,4\% em UTIs (PELEG AY, et al., 2008).

Nos leitos de UTI, encontra-se o principal grupo de risco de infecção, não apenas porque estar intrinsecamente mais vulnerável, mas também pela ameaça de contrair uma infecção nosocomial e sepse. No rol das principais infecções, as mais comuns, na larga maioria dos casos, correlacionam-se com procedimentos invasivos, tais como cateter vesical, ventilação mecânica, cirurgias complexas, cateterismo 
venoso central, drogas imunossupressoras, monitoramento invasivo da pressão central, antimicrobianos e as interações com a equipe de saúde e os fômites (COUTO RC, et al., 2003). Por consequência, pacientes admitidos em UTIs estão sujeitos a riscos de 5 a 10 vezes maior de adquirir infecção, se comparado com pacientes de outros setores (MOURA ME, et al., 2007).

Ao comparar a incidência de infecções associadas ao uso de dispositivos invasivos em 939 pacientes em UTIs de diferentes hospitais por dois anos, um estudo na Turquia encontrou $61,54 \%$ de contaminação de Staphylococcus aureus resistente à meticilina (MRSA) e taxa de Beta-lactamase de espectro estendido (ESBL) em E. coli e Klebsiella foi de 48,72\% (DERELI N, et al., 2013).

Outro estudo realizado em duas UTIs de um hospital público de ensino de Teresina por Moura ME, et al. (2007); no estado do Piauí, com 394 casos infecção nosocomial, constatou que a infecção respiratória teve a maior prevalência $(61,26 \%)$, em concomitância, o microorganismo com maior prevalência foi a $K$. pneumoniae $(35,46 \%)$. Sobre as mortalidades atribuídas às IRAS, sobretudo em setores com pacientes hemodinamicamente instáveis, como as UTIs, admite-se que a infecção nosocomial representa um marcador para pacientes com maior risco de morte, como coloca Fagon JY, et al. (1994); isso porque o risco de infecção é diretamente proporcional à gravidade da doença.

Desta forma, cabe inferir o papel das IRAS no aumento da mortalidade em UTIs, como visto em um estudo vinculado ao Departamento de Enfermagem da Universidade de São Paulo, em que a taxa de mortalidade em pacientes que adquiriram infecção hospitalar correspondeu a 57,5\% enquanto que em paciente sem infecção a taxa foi de 8,3\% (LIMA ME, et al., 2007).

Outra ocorrência que merece destaque é a Infecção de Sítio Cirúrgico (ISC), que é hoje um dos principais riscos à segurança dos pacientes nos serviços hospitalares no Brasil, sua ocorrência ocupa o $3^{\circ}$ lugar entre as IRAS, compreendendo $14 \%$ a $16 \%$ daquelas encontradas em pacientes hospitalizados; em seguida, a Infecção do Trato Respiratório (ITR) representa 39\% do total de infecções hospitalares (ANVISA, 2017).

Uma avaliação microbiológica realizada na Universidade Federal de Pernambuco (UFPE) verificou que $88 \%$ dos celulares de profissionais de saúde que frequentavam as salas de cirurgia estavam contaminados (CUNHA CBC, et al., 2016). Presume-se o risco de ISC como proporcional à duração do procedimento cirúrgico e estima-se que a incidência aumenta aproximadamente duas vezes a cada hora de duração da cirurgia (CRUSE PJE e FOORD R, 1980).

Micro-organismos que naturalmente colonizam a pele de indivíduos saudáveis, como por exemplo, o Staphylococcus epidermidis, que é uma variedade de Staphylococcus coagulase-negativa (SCN), são considerados oportunistas, já que em pacientes com o sistema imunológico enfraquecido estão associados às infecções dos sítios de pele, feridas cirúrgicas e sangue (ANVISA, 2017).

Essa grande incidência deve-se, sobretudo, à sua capacidade de colonizar dispositivos intravasculares, próteses, grandes feridas, assim multiplicando-se e ganhando resistência ao tratamento convencional com antibióticos. Para o gênero Staphylococcus, o $S$. aureus e $S$. epidermidis são as duas espécies que merecem especial atenção pois relacionam-se determinantemente com diferentes tipos de infecção hospitalar (LOWY FD, 1998).

Em específico, o S. epidermidis, no contexto das ISCs, é ainda mais grave, pois é um agente etiológico relacionado à diversas infecções nosocomiais (bacteremia, endocardite, osteomielite, peritonite, infecções cardíacas pós-operatórias, infecções do trato urinário), e que está frequentemente associado à colonização de cateteres e implantes. Grande parte dos países desenvolvidos tem relatado o aumento de infeções por SCN resistentes à meticilina e à emergência de cepas multirresistentes endêmicas no ambiente hospitalar (MICHELIM L, et al., 2005).

Outro gênero de microorganismo cujo número de infecções tem aumentado nos últimos anos é o Acinetobacter, principalmente a espécie $A$. baumannii, tipo de maior importância, capaz de causar infecções comunitárias e, sobretudo, nosocomiais (CIELO G e ARAÚJO M, 2016). Os fatores de risco para 
a infecção por $A$. baumannii têm origem, na maioria dos casos, nos procedimentos invasivos, como, por exemplo, o cateter venoso central, cateter urinário ou ventilação mecânica. Os principais sítios de infecção por A. baumannii são o trato urinário, pulmões, sangue e feridas cirúrgicas (ANVISA, 2017).

Pela sua capacidade de manter-se por extensos períodos na superfície de objetos no ambiente nosocomial, o $A$. baumannii representa o risco aumentado de um surto infeccioso, relatado por Ferreira $\mathrm{H}$ e Lala ER (2009); como o ocorrido em Porto Alegre em 2007, quando vários hospitais notificaram casos de infecção por Acinetobacter spp., e que constituiu um surto de infecção nosocomial por este microorganismo. É premente ressaltar que após a introdução desse patógeno resistente no ambiente hospitalar, a erradicação completa nem sempre é possível, o que geralmente incide em níveis endêmicos do microrganismo (ROESCH EW, 2017).

O uso dos aparelhos celulares em unidades de saúde é um tema que suscita divergências, pois operam na interseção entre os serviços de saúde e informações da internet, englobando informática médica e saúde pública, como discutido por Eysenbach G (2001); ao mesmo tempo representam um potencial fator de risco para infecções, já que bactérias podem ser transportadas do meio externo para o meio interno das unidades hospitalares (COIMBRA JA, et al., 2020). Neste contexto, cabe investigar as IRAS, um problema de saúde pública, relacionadas ao telefone celular, como um possível reservatório de patógenos e disseminação de bactérias no ambiente nosocomial (CUNHA CBC, et al., 2016).

A partir das informações expostas e trabalhos que situam a infecção hospitalar entre as principais complicações que afetam o paciente hospitalizado, como descreve Burke JP (2003); este estudo propõese a determinar a existência de quatro microorganismos relevantes dentro do ambiente hospitalar e coletados da superfície dos celulares dos profissionais de saúde, são eles: K. pneumoniae, A. baumannii, Staphylococcus aureus resistente à meticilina (MRSA) e Staphylococcus coagulase-negativa (SCN) nos setores selecionados.

\section{MÉTODOS}

Foram coletadas amostras de 120 aparelhos celulares de profissionais de saúde com diferentes formações que atuam em um hospital da Baixada Fluminense no estado do Rio de Janeiro, entre os meses de outubro e novembro de 2019. São 30 amostras de profissionais do Centro Cirúrgico, 30 de profissionais da UTI, 30 amostras da Emergência e outras 30 amostras de funcionários administrativos constituindo o grupo de controle. Trata-se de um estudo descritivo e analítico de uma população que atua em setores distintos de um mesmo hospital.

Os critérios de inclusão foram: ser maior de 18 anos, ser profissional de saúde dentro dos setores indicados, portar aparelho celular dentro do setor de trabalho; Critérios de exclusão: não ser profissional de saúde, não ser funcionário do setor indicado, declarar não portar aparelho celular dentro do setor, recusarse a participar da pesquisa. Todos os participantes assinaram o Termo de Consentimento Livre e Esclarecido (TCLE), condição também obrigatória para participar deste estudo. Este estudo recebeu aprovação do Comitê de Ética em Pesquisa (CEP) da Universidade Iguaçu (UNIG) sob a numeração de CAAE: 14228319.7.0000.8044. Para obtenção das amostras, foram utilizados swab estéril e luvas de látex.

Após o contato com a parte posterior dos aparelhos, os swabs foram inseridos em um tubo estéril identificado, contendo Caldo tioglicolato e acondicionados para o transporte. Todas as amostras foram enviadas para o laboratório de análise no mesmo dia da coleta. Os testes de esterilidade foram feitos em Teste de esterilidade: Caldo Tioglicolato com indicador de resazurina (Plast Labor).

No laboratório foram utilizados meios cromogênicos da marca Plast Labor, senso eles os seguintes: Ágar Sangue de Carmesin 52, Ágar Cromaclin, Ágar Cromo ESBL, Ágar Cromo Acineto, Ágar Cromo MRSA, Ágar Mackonkey, Ágar Manita Sal que fizeram a identificação dos quatro patógenos selecionados: Klebsiella pneumoniae, Acinetobacter baumannii, Staphylococcus aureus resistentes à meticilina (MRSA) e Staphylococcus coagulase-negativa (SCN). A análise dos resultados concentrou-se na comparação entre os setores hospitalares investigados. 


\section{RESULTADOS}

A abrangência da amostra incluiu 120 profissionais de 4 setores distintos dentro do hospital. A inclusão dos funcionários deu-se pela abordagem aleatória dentro do setor e incluídos por aceite de participação no estudo, desde cumprissem com as condições já descritas em Materiais e Métodos. As coletas foram realizadas dos celulares de 30 médicos (12 do centro cirúrgico, 12 da UTI, 6 da emergência), 16 enfermeiros ( 7 na emergência, 5 na UTI e 04 no centro cirúrgico) e 44 técnicos de enfermagem (17 na emergência, 14 no centro cirúrgico e 13 na UTI); Outras 30 amostras, para o grupo de controle, foram coletadas de profissionais de cargos administrativos.

A positividade total para a contaminação dos aparelhos, por pelo ao menos um tipo de microorganismo patogênico, foi de $92,5 \%$ (111). O alto número de amostras contaminadas evidente nos resultados, não apresentou diferenças significativas de frequência como evidenciado na Tabela 1. Do total de 120 amostras coletadas de funcionários de quatro setores do hospital (Centro Cirúrgico, Emergência, UTI e Administrativo: este último constituindo o grupo de controle), os maiores percentuais de contaminação foram da UTI e grupo controle, ambos com 96,6\% dos aparelhos contaminados (Tabela 1). O Centro Cirúrgico apresentou $93,3 \%$ dos aparelhos contaminados e a Emergência $83,3 \%$. Os resultados negativos são de 7,5\% (9) das amostras.

Tabela 1 - Distribuição dos resultados por setor hospitalar.

\begin{tabular}{cccccc}
\hline & Administrativo & $\begin{array}{c}\text { Centro } \\
\text { Cirúrgico }\end{array}$ & Emergência & UTI & $\begin{array}{c}\text { Total } \\
\text { geral }\end{array}$ \\
\hline Positivo & $29(96,6 \%)$ & $28(93,3 \%)$ & $25(83,3 \%)$ & $29(96,6 \%)$ & $\mathbf{1 1 1}(\mathbf{9 2 , 5} \%)$ \\
\hline Negativo & $1(3,4 \%)$ & $2(6,6 \%)$ & $5(16,6 \%)$ & $1(3,4 \%)$ & $\mathbf{9 ( 7 , 5 \% )}$ \\
\hline
\end{tabular}

Fonte: Netto HS, et al., 2020.

Ao analisar os resultados a partir da ocupação dos participantes (Tabela 2), foi possível observar que não houve diferença significativa de frequência, embora chame atenção que o grupo controle apresente o maior percentual de contaminação total.

Tabela 2 - Positividade por ocupação.

\begin{tabular}{lcccc} 
& Administrativo & Médicos & Enfermeiros & $\begin{array}{c}\text { Técnicos de } \\
\text { Enfermagem }\end{array}$ \\
\hline Positivo & $29(96,6 \%)$ & $28(93,3 \%)$ & $14(87,5 \%)$ & $40(91 \%)$ \\
\hline Negativo & $1(3,4 \%)$ & $2(6,6 \%)$ & $2(12,5 \%)$ & $4(9 \%)$ \\
\hline
\end{tabular}

Fonte: Netto HS, et al., 2020.

Os aparelhos contaminados por um tipo de bactéria representam $48,3 \%$ da amostra total, enquanto os aparelhos com dois tipos de bactérias foram $43,3 \%$ e apenas um $(7,5 \%)$ aparelho apresentou contaminação por três tipos de bactéria (Tabela 3). O aparelho que apresentou os três tipos de colônia bacteriana, oriundo do setor de UTI, o setor geralmente é o mais acometido por IRAS com infecção por cateteres venosos e pneumonia associada à ventilação mecânica (DERELI N, et al., 2013). Os tipos bactérias neste caso de infecção múltipla, são: Acinetorbacter baumannii, Staphylococcus aureus e Enterococcus faecalis.

Tabela 3 - Percentual de celulares com contaminação múltipla.

\begin{tabular}{cc}
\hline Número de tipos de bactérias & Frequência \\
\hline 1 & $58(48,3 \%)$ \\
\hline 2 & $52(43,3 \%)$ \\
\hline 3 & $1(8 \%)$ \\
\hline Negativos & $9(7,5 \%)$ \\
\hline
\end{tabular}

Fonte: Netto HS, et al., 2020. 
Diversos estudos em todo o mundo têm evidenciado altos percentuais de contaminação dos aparelhos portados por funcionários de hospitais, como relatado por BISHT M, et al. (2018); esse prognóstico se confirmou também no hospital estudado. Foram achados patógenos de relevância clínica, inclusive dentro do cenário da infecção hospitalar em um hospital de alta complexidade. O tipo de bactéria predominante foi o Staphylococcus coagulase-negativa (51\%), seguido do Staphylococcus aureus MRSA (6\%), Acinetobacter baumannii (3,3\%) e Klebsiella pneumoniae (1,6\%).

Cada celular teve resultados individualizados. Laudo que consiste de nome do proprietário do celular e cultura positiva ou negativa. Culturas negativas, segundo percepção durante a coleta e observação, apontam a higienização prévia do dispositivo, o que é compreensível face a preocupação com a coleta dentro do ambiente de trabalho.

Tabela 4 - Percentual de contaminação por tipo de bactéria.

\begin{tabular}{ccc}
\hline Tipo de Bactéria & Total & $\%$ \\
\hline Staphylococcus epidermidis & 61 & $51 \%$ \\
\hline Staphylococcus aureus & 51 & $42,5 \%$ \\
\hline Enterococcus faecalis & 23 & $19 \%$ \\
\hline Enterobacter clocae & 14 & $11,6 \%$ \\
\hline Staphylococcus aureus MRSA & 7 & $6 \%$ \\
\hline Acinetobacter baumannii & 4 & $3,3 \%$ \\
\hline Escherichia coli & 3 & $2,5 \%$ \\
\hline Klebsiella pneumoniae & 2 & $1,6 \%$ \\
\hline
\end{tabular}

Fonte: Netto HS, et al., 2020.

O Staphylococcus coagulase-negativa (SCN) foi a bactéria mais encontrada, sendo o Staphylococcus epidermidis a espécie mais frequentemente isolada (51\%). Sete amostras foram positivas para Staphylococcus aureus MRSA, quatro amostras foram positivas para Acinetobacter baumannii e 2 amostras positivas para Klebsiella pneumoniae.

O Staphylococcus coagulase-negativa (SCN) foi o germe com maior ocorrência de concomitância com outras bactérias, foram 34 ocorrências (Tabela 5). Outras concomitâncias verificadas em menor número foram: Acinetobacter baumanni e Staphylococcus aureus (2), Acinetobacter baumannii e Enterococcus faecalis (1); Klebsiella pneumoniae e Enterococcus faecalis (1), Klebsiella pneumoniae e Enterobacter cloacae (1); Staphylococcus aureus MRSA e Enterobacter cloacae (1).

Tabela 5 - Bactérias encontradas em concomitância com outros tipos.

\begin{tabular}{ccc}
\hline Bactéria encontrada & Total & $\%$ \\
\hline Staphylococcus epidermidis + S. Aureus & 19 & $16 \%$ \\
\hline Staphylococcus epidermidis + E. faecalis & 8 & $6,5 \%$ \\
\hline Staphylococcus epidermidis + E. cloacae & 5 & $4 \%$ \\
\hline Staphylococcus epidermidis + E. coli & 2 & $1,6 \%$ \\
\hline Total & 34 & $28 \%$
\end{tabular}

Fonte: Netto HS, et al., 2020.

A avaliação por setores evidencia o alto grau de contaminação no grupo controle, representado pelos funcionários administrativos (Tabela 6). 
Tabela 6 - Contaminação por setor hospitalar e tipo de bactéria.

\begin{tabular}{|c|c|c|c|c|c|c|}
\hline \multicolumn{7}{|c|}{ Setor Hospitalar } \\
\hline Resultado Positivo & Administrativo & $\begin{array}{c}\text { Centro } \\
\text { Cirúrgico }\end{array}$ & Emergência & UTI & Total & $\%$ \\
\hline Staphylococcus aureus & 14 & 12 & 14 & 11 & 51 & $42,5 \%$ \\
\hline Staphylococcus epidermidis & 15 & 18 & 14 & 14 & 61 & $51 \%$ \\
\hline Staphylococcus aureus MRSA & 3 & 2 & 0 & 2 & 7 & $6 \%$ \\
\hline Enterococcus faecalis & 6 & 5 & 6 & 6 & 23 & $19 \%$ \\
\hline Acinetobacter baumannii & 0 & 0 & 0 & 4 & 4 & 3,3 \\
\hline Enterobacter clocae & 4 & 3 & 4 & 3 & 14 & $11,5 \%$ \\
\hline Klebsiella pneumoniae & 1 & 0 & 1 & 0 & 2 & $1,6 \%$ \\
\hline Escherichia coli & 0 & 0 & 1 & 2 & 3 & $2,5 \%$ \\
\hline
\end{tabular}

Fonte: Netto HS, et al., 2020.

\section{DISCUSSÃO}

Foi encontrado o Staphylococcus coagulase-negativa em 51\% dos aparelhos e o Staphylococcus aureus em mais de $40 \%$ deles. Em percentuais inferiores, encontramos o Staphylococcus aureus resistente à meticilina nos dispositivos, o que reforça o papel do objeto no interior do hospital como potencial fonte de contaminação. Acinetobacter baumannii, causa de infecções hospitalares dignas de nota, também foram encontradas em quatro aparelhos, todos, cabe ressaltar, dentro da UTI. Como reconhecido em diversos estudos em todo o mundo, a maioria das bactérias gram-positivas, quanto gram-negativas, são capazes de sobreviver por meses em superfícies de fômites (KRAMER A, et al., 2006).

Outro aspecto importante e inesperado foi a importante participação na positividade do total de aparelhos, observada em nossa amostra de controle, que seriam os celulares do pessoal administrativo. Isso evidencia para como o manuseio de documentos, num sistema ainda não totalmente informatizado, com pastas e formulários que circulam por setores diversos, pode contribuir para a circulação de uma infecção. A discussão a respeito do desenvolvimento do prontuário eletrônico é um tema bastante relevante no cenário nosocomial, alguns estudos afirmam que a informatização desse processo pode melhorar a qualidade do cuidado à saúde, como especificado por Rodrigues F, et al. (2001); e desde já mostra-se necessária a sua integração às estratégias globais de combate às IRAS.

Como os dados obtidos evidenciam, além do risco de infecção para os próprios funcionários, nesta situação, há também o risco de contaminação de pacientes, já que os documentos que circulam, retornam aos setores médicos. Medidas simples, como lavar as mãos, amplamente divulgadas no desafio "Uma Assistência Limpa é Uma Assistência Mais Segura" proposto pela Organização Mundial de Saúde (OMS), são direcionadas para ações de melhoria de higienização das mãos nos serviços de saúde. Há também o "Cirurgias Seguras Salvam Vidas", também proposto pela OMS com o objetivo de estimular boas práticas de higiene em procedimentos cirúrgicos.

Para citar um exemplo dos riscos oferecidos pelas infecções nosocomiais e seus desdobramentos, é preciso mencionar as projeções de longo prazo do Instituto Brasileiro de Geografia e Estatística (IBGE) sobre a transição demográfica prevista para o Brasil, discutidas por Malta D, et al. (2006); que apontam para a desaceleração no ritmo de crescimento e uma consequente inversão da nossa pirâmide etária. Nesse cenário, a expectativa é de que o número de pessoas com 65 anos ou mais praticamente triplique, chegando a 58,2 milhões em 2060 - o equivalente a $25,5 \%$ da população. Já em 2039 o número de idosos com mais de 65 anos superará o de crianças de até 14 anos, o que deve acelerar a trajetória de envelhecimento da população (IBGE, 2018).

Este aumento da expectativa de vida do brasileiro, alerta também para a importância crescente de doenças crônicas entre as causas de mortalidade, o que consequentemente tem como efeito o aumento das hospitalizações e de procedimentos cirúrgicos. Em pacientes idosos as barreiras das mucosas sofrem 
alterações que as deixam expostas à infecções em que a colonização se inicia na orofaringe. Assim, microorganismos como a Klebsiella pneumoniae, Escherichia coli e Staphylococcus aureus, são agentes responsáveis pelas principais doenças infecciosas que acometem os idosos no Brasil: a pneumonia e a infecção de trato urinário (GOMES L, 2001). O uso indiscriminado de antimicrobianos e o consequente surgimento de resistência bacteriana a essas drogas representam um desafio a mais (KALACHE A, 2016).

Outro tema de extrema relevância é a resistência cruzada de bactérias em ambientes nosocomiais, entre pacientes através de instrumentos hospitalares ou através do profissional da saúde, que neste caso atua como um intermediário. Medidas como a lavagem das mãos e uso de antissépticos são preconizados pelo Centers for Disease Control and Prevention (CDC) com o objetivo de reduzir a ocorrência das infecções hospitalares, evitando, a disseminação (CDC, 2002). É necessário, sobretudo, o uso eficiente e controlado de drogas antimicrobianas para que não ocorra a seleção e a disseminação de microrganismos resistentes no ambiente hospitalar.

Embora grande parte dos estudos preconizem o uso racional do celular em ambientes que envolvam práticas de saúde, essa é uma medida difícil a se fazer cumprir, já que além dos usos e costumes correntes, as implicações da apropriação dos wearables nos cuidados com a saúde tornam cada dia mais integradas ao corpo e capazes de processar informações e sinais do corpo humano e gerando um fluxo de informação constante e instantânea (FANTONI A, 2016). A relação com esses dispositivos tecnológicos é cada vez mais intrincada com funcionalidades ligadas à saúde e é necessário que cada instituição avalie quando os ganhos com o seu uso superam os potenciais riscos para a saúde dos pacientes e comunidade hospitalar.

\section{CONCLUSÃO}

Constatou-se que os patógenos nosocomiais mais comuns podem colonizar as superfícies dos aparelhos celulares, constituindo, assim, uma fonte contínua de transmissão, caso nenhuma desinfecção preventiva e regular da superfície dos aparelhos seja realizada. Em concordância com a bibliografia publicada sobre este assunto, telefones celulares podem servir como agentes carreadores de bactérias potencialmente patogênicas, desta forma, medidas que normatizem a desinfecção regular dos aparelhos, bem como a higienização previa das mãos, fazem-se urgentes, assim como a discussão a respeito da regulamentação do seu uso no ambiente hospitalar.

\section{AGRADECIMENTOS}

Como discente, agradeço em primeiro lugar à Universidade Iguaçu (UNIG); como bolsista, agradeço imensamente ao Programa de Iniciação Científica (PIC - UNIG) que tem me incentivado e provido todo o suporte necessário para o meu desenvolvimento acadêmico.

\section{REFERÊNCIAS}

1. ANVISA - Agência Nacional de Vigilância Sanitária. Critérios Diagnósticos de Infecção Relacionada à Assistência à Saúde. Série: Segurança do Paciente e Qualidade em Serviços de Saúde. Brasília: 2017.

2. ANVISA - Agência Nacional De Vigilância Sanitária. Gvims/Ggtes/Anvisa, 2016; Cnes/Ms, 2016. Boletim de Segurança do Pacientee Qualidade em Serviços de Saúde no 16 (corrigido). Brasília; 2016.

3. ANVISA - Agência Nacional De Vigilância Sanitária. Manual de Microbiologia Clínica para o Controle de Infecção em Serviços de Saúde. Brasília; 2004.

4. BISHT M, et al. Microbial contamination of mobile phones of health care providers at a teaching hospital in a hilly North Indian State. Indian Journal of Community and Family Medicine. 4. 34, 2018.

5. BRASIL. Ministério da Saúde. Expede na forma de anexos diretriz e normas para a prevenção e controle das infecções hospitalares: Portaria № 2.616, de 12 de maio de 1998. Diário Oficial da União, República Federativa do Brasil, Brasília (DF), julho, 1998.

6. BURKE JP. Infection Control - A Problem for Patient Safety. The New England Journal of Medicine 2003;348(7).

7. CDC - Centers For Disease Control And Prevention. Healthcare-associated Infections (HAI) Progress Report. 2016.

8. CIELO G, ARAÚJO M. Perfil epidemiológico do Acinetobacter baumannii resistente a carbapenens num hospital do interior mineiro. Revista Família, Ciclos de Vida e Saúde no Contexto Social, 2016. 
9. COIMBRA JA, et al. Taxa de Infecção Bacteriana em Aparelhos Telefônicos em Centro de Tratamento Intensivo em Hospital Universitário De Belo Horizonte. Revista Interdisciplinar Ciências Médicas. 2020; 4: 2.

10. COUTO RC, et al. Infecção Hospitalar - Epidemiologia, controle e tratamento. 3ª ed. Rio de Janeiro (RJ): Editora Médica e Científica; 2003.

11. CRUSE PJE, FOORD R. The epidemiology of wound infection: a 10-year prospective study of 62,939 wounds. Surg. Clin. North. Am. 1980.

12. CUNHA CBC, et al. Avaliação microbiológica dos aparelhos celulares de profissionais do Bloco Cirúrgico em um Hospital beneficente. Revista de Epidemiologia e Controle de Infecção, Santa Cruz do Sul, 2016; 6: 3.

13. DERELI N, et al. Três anos de avaliação das taxas de infecção nosocomial em UTI. Revista Brasileira de Anestesiologia, 2013.

14. EYSENBACH G. What is e-health? In: Journal of Medical Internet Research, 2001; 3(2): e20.

15. FAGON JY, et al. Mortality attributable to nosocomial infections in the ICU. Infection Control \& Hospital Epidemiology, 1994.

16. FANTONI A. Dispositivos wearable para o campo da saúde: reflexões acerca do monitoramento de dados do corpo humano. NAMID/UFPB (PB), 2016; XII: 01.

17. FERREIRA H, LALA ER. Pseudomonas aeruginosa: Um alerta aos profissionais de saúde. 2009. Tese (Doutorado) Departamento de Enfermagem, Universidade Estadual do Oeste do Paraná - Unioeste, Foz do Iguaçu, 2010.

18. FOURNIER PE, RICHET H. The epidemiology and control of Acinetobacter baumannii in health care facilities. Clinical Infectious Diseases 2006; 42: 692-9.

19. GOMES L. Fatores de risco e medidas profiláticas nas pneumonias adquiridas na comunidade. J. de Pneumologia. Março, 2001.

20. KALACHE A. Respondendo à revolução da longevidade. Ciência Saúde Coletiva, Rio de Janeiro, 2014; 19(8): 3306.

21. KEMPF M, ROLAIN JM. Emergence of resistance to carbapenems in Acinetobacter baumannii in Europe: clinical impact and therapeutic options. International Journal of Antimicrobial Agents, 2012.

22. KRAMER A, et al. Quanto tempo os patógenos nosocomiais persistem em superfícies inanimadas? Uma revisão sistemática. BMC Infect Dis, 2006; 6: 130.

23. LIMA ME, et al. Avaliação prospectiva da ocorrência de infecção em pacientes críticos de unidade de terapia intensiva. Revista Brasileira de Terapia Intensiva, 2007; 19(3): 342-347.

24. LOWY FD. Staphylococcus aureus infections. New England Journal Med. 1998; 20: 520-32.

25. MALTA D et al. A construção da vigilância e prevenção das doenças crônicas não transmissíveis no contexto do Sistema Único de Saúde. Epidemiologia e Serviços de Saúde. 2006; $15: 1$.

26. MICHELIM L, et al. Fatores de patogenicidade e resistência a antimicrobianos em Staphylococcus epidermidis associados a infecções nosocomiais em unidades de terapia intensiva. Brazilian Journal of Microbiology, 2005; 36(1): 17-23.

27. MORAES CL, et al. Contaminação de equipamentos por Staphylococcus coagulase-negativo em unidades de terapia intensiva de uma maternidade pública. Revista De Patologia Tropical, 2013.

28. MOURA ME, et al. Infecção hospitalar: estudo de prevalência em um hospital público de ensino. Revista Brasileira de Enfermagem, 2007.

29. OLIVEIRA AC, DAMASCENO QS. Superfícies do ambiente hospitalar como possíveis reservatórios de bactérias resistentes: uma revisão. Rev. Esc. Enferm. USP, São Paulo, 2010; 44: 4.

30. OLIVEIRA AC, et al. Infecções relacionadas à assistência em saúde: desafios para a prevenção e controle. REME: Revista Mineira de Enfermagem, Belo Horizonte, 2009; 13(3): 445-450.

31. PELEG AY, et al. Acinetobacter baumannii: Emergence of a successful pathogen. Clinical Microbiology Reviews, 2008; $21(3): 538-582$.

32. PRADES SS, et al. Estudo brasileiro da magnitude das infecções hospitalares em hospital terciário. Revista Controle Infecção Hospitalar.1995.

33. RODRIGUES F, et al. A tecnologia da informação na área hospitalar: um caso de implementação de um sistema de registro de pacientes. Revista Administração Contemporânea, 2001; 5(1): 105-120.

34. ROESCH EW. Importância da pressão de colonização bacteriana e da pressão seletiva do uso de antimicrobianos na aquisição de isolados de Acinetobacter baumannii multirresistente em unidades de terapia intensiva. Tese de Doutorado - Instituto de Biociências. Universidade Federal do Rio Grande do Sul, Porto Alegre, 2017.

35. VARELA APAS, VELOSO G. Avaliação microbiológica dos aparelhos celulares de acompanhantes em unidade de terapia intensiva: uma revisão bibliográfica. Hospital Regional Público do Sudeste do Pará. Marabá - PA. Outubro, 2018. 